Article

\title{
Synthesis and Crystal Structures of $\mathrm{N}$-Substituted Pyrazolines
}

\author{
Wan-Sin Loh ${ }^{1}$, Ching Kheng Quah ${ }^{1}$, Tze Shyang Chia ${ }^{1}$, Hoong-Kun Fun ${ }^{1,2, *}$, \\ Majal Sapnakumari ${ }^{3}$, Badiadka Narayana ${ }^{3}$ and Balladka Kunhanna Sarojini ${ }^{4}$ \\ 1 X-ray Crystallography Unit, School of Physics, Universiti Sains Malaysia, \\ Penang 11800 USM, Malaysia \\ 2 Department of Pharmaceutical Chemistry, College of Pharmacy, King Saud University, \\ Riyadh 11451, Saudi Arabia \\ 3 Department of Studies in Chemistry, Mangalore University, Mangalagangotri-574 199, India \\ 4 Department of Chemistry, P.A. College of Engineering, Nadupadavu, Mangalore-574 153, India \\ * Author to whom correspondence should be addressed; E-Mail: hfun.c@ksu.edu.sa; \\ Tel.: +966-1467-7335; Fax: +966-1467-6220.
}

Received: 12 December 2012; in revised form: 2 February 2013 / Accepted: 7 February 2013 / Published: 20 February 2013

\begin{abstract}
Four pyrazole compounds, 3-(4-fluorophenyl)-5-phenyl-4,5-dihydro-1Hpyrazole-1-carbaldehyde (1), 5-(4-bromophenyl)-3-(4-fluorophenyl)-4,5-dihydro-1H-pyrazole1-carbaldehyde (2), 1-[5-(4-chlorophenyl)-3-(4-fluorophenyl)-4,5-dihydro-1H-pyrazol-1yl]ethanone (3) and 1-[3-(4-fluorophenyl)-5-phenyl-4,5-dihydro-1H-pyrazol-1-yl]propan1-one (4), have been prepared by condensing chalcones with hydrazine hydrate in the presence of aliphatic acids, namely formic acid, acetic acid and propionic acid. The structures were characterized by X-ray single crystal structure determination. The dihedral angles formed between the pyrazole and the fluoro-substituted rings are $4.64(7)^{\circ}$ in 1 , 5.3(4) $)^{\circ}$ in 2 and $4.89(6)^{\circ}$ in 3. In 4, the corresponding angles for molecules $A$ and molecules $B$ are $10.53(10)^{\circ}$ and $9.78(10)^{\circ}$, respectively.
\end{abstract}

Keywords: synthesis; X-ray diffraction; pyrazole; crystal structure

\section{Introduction}

The reaction of chalcones with hydrazine derivatives is one of the most extensively applied reactions in organic synthesis. Investigations revealed that in most cases the products formed are 
pyrazoline derivatives [1-4]. However, the reactions may also produce pyrazole derivatives [5] and Schiff base hydrazones [6]. These reactions are usually carried out in an acidic medium.

Pyrazoline derivatives display various biological activities such as antitumor, antifungal, antiviral, antiparasitic, anti-inflammatory and analgesic, antimycobacterial, anticancer, antibacterial, insecticidal, antinociceptive, hypotensive, antidepressant, photoluminiscence, anti-tubercular, antiamoebic, MAO-inhibitory, amine oxidase inhibitory and antioxidant properties [7-9]. Several 1,3,5-triaryl-2-pyrazoline derivatives were also used as scintillation solutes [10]. Pyrazoline derivatives with a phenyl group at the 5-position have been shown to possess good film-forming properties and exhibit excellent characteristics of blue photoluminescence, fluorescence and electroluminescence [11].

In view of importance of pyrazolines and in continuation of our work on the synthesis and structure determination of various pyrazoline derivatives [12-15], we report the synthesis and crystal structures of four novel $N$-substituted pyrazolines.

\section{Results and Discussion}

One of the most convenient methods for the synthesis of pyrazolines is the reaction of $\alpha, \beta$-unsaturated ketones with hydrazine hydrate and its derivatives. New $N$-substituted pyrazolines, 1-4 have been synthesized by the reaction of respective chalcone with hydrazine hydrate in the presence of different aliphatic acids as shown in Scheme 1. The crystallographic data for the four compounds are listed in Table 1.

Scheme 1. Preparation of $N$-substituted pyrazoline compounds.

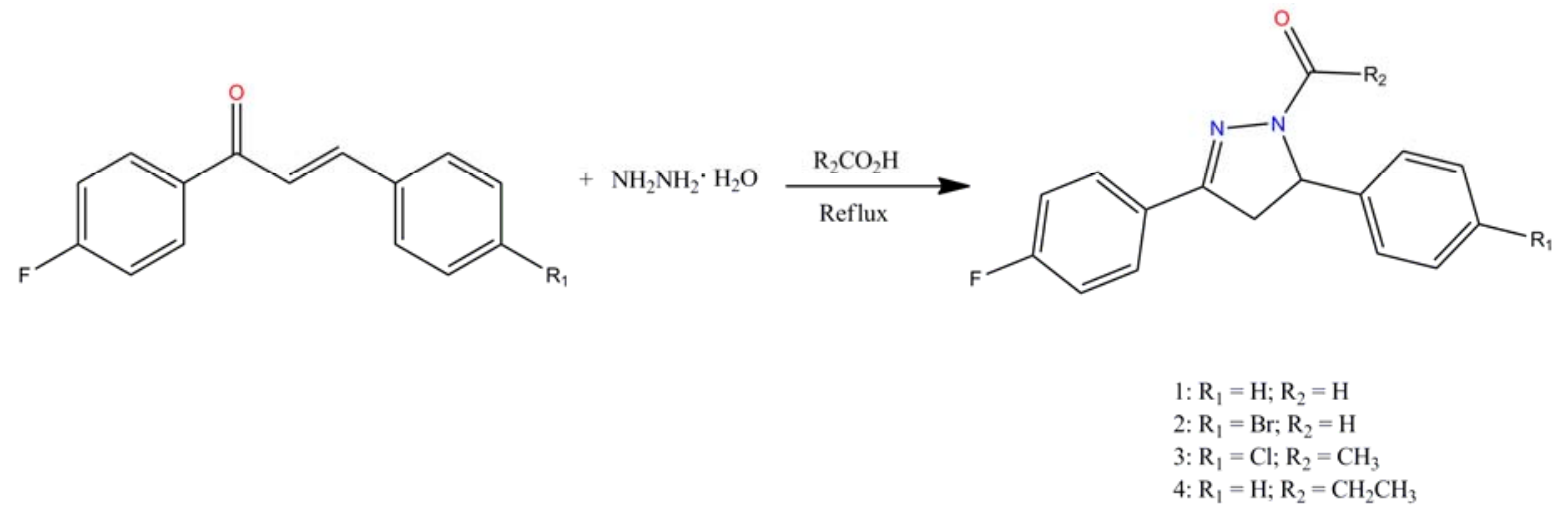

\subsection{Crystal Structure Description of Compound 1}

The molecular structure of $\mathbf{1}$ is depicted in Figure 1a. The pyrazole ring (N1/N2/C7-C9) is almost planar with a r.m.s deviation of $0.0457 \AA$. This ring forms a dihedral angle of $4.64(7)^{\circ}$ with the fluoro-substituted benzene ring $(\mathrm{C} 1-\mathrm{C} 6)$ and is almost perpendicular with the benzene ring $(\mathrm{C} 10-\mathrm{C} 15)$, with a dihedral angle of $84.83(7)^{\circ}$. Bond lengths and angles are within the normal ranges [16]. In the crystal structure of $\mathbf{1}$, the molecules are linked into planes parallel to the $a b$-plane by intermolecular $\mathrm{C}-\mathrm{H} \cdots \mathrm{O}$ hydrogen bonds as shown in Figure $2 \mathrm{a}$ (Table 2). These planes are further linked into a threedimensional network by intermolecular $\mathrm{C}-\mathrm{H} \bullet \bullet \mathrm{F}$ hydrogen bonds (Figure 2b; Table 2). 
Table 1. Crystal data and parameters for structure refinement of 1, 2, 3 and 4.

\begin{tabular}{|c|c|c|c|c|}
\hline Compound & 1 & 2 & 3 & 4 \\
\hline CCDC deposition numbers & 895315 & 895316 & 895317 & 895318 \\
\hline Molecular formula & $\mathrm{C}_{16} \mathrm{H}_{13} \mathrm{FN}_{2} \mathrm{O}$ & $\mathrm{C}_{16} \mathrm{H}_{12} \mathrm{BrFN}_{2} \mathrm{O}$ & $\mathrm{C}_{17} \mathrm{H}_{14} \mathrm{ClFN}_{2} \mathrm{O}$ & $\mathrm{C}_{18} \mathrm{H}_{17} \mathrm{FN}_{2} \mathrm{O}$ \\
\hline Molecular weight & 268.28 & 347.19 & 316.75 & 296.34 \\
\hline Crystal system & Monoclinic & Monoclinic & Monoclinic & Triclinic \\
\hline Space group & $C c$ & $C c$ & $P 2_{1} / c$ & $P \overline{1}$ \\
\hline$a / \AA ̊$ & $11.9069(7)$ & $6.2375(14)$ & $6.1087(4)$ & $9.3334(2)$ \\
\hline$b / \AA$ & $6.2516(4)$ & $12.191(3)$ & $12.3725(9)$ & $13.2760(3)$ \\
\hline$c / \AA$ & $17.3103(10)$ & $18.703(4)$ & $19.6142(14)$ & $13.2857(3)$ \\
\hline$\alpha /{ }^{\circ}$ & 90 & 90 & 90 & $107.052(1)$ \\
\hline$\beta /{ }^{\circ}$ & $98.737(1)$ & $93.239(5)$ & $97.769(1)$ & $95.124(1)$ \\
\hline$\gamma /{ }^{\circ}$ & 90 & 90 & 90 & $96.629(1)$ \\
\hline$V / \AA^{3}$ & $1273.58(13)$ & $1419.9(6)$ & $1468.83(18)$ & $1550.14(6)$ \\
\hline$Z$ & 4 & 4 & 4 & 4 \\
\hline$D_{\text {calc }}\left(\mathrm{g} \mathrm{cm}^{-3}\right)$ & 1.399 & 1.624 & 1.432 & 1.270 \\
\hline Crystal Dimensions (mm) & $0.19 \times 0.32 \times 0.46$ & $0.13 \times 0.29 \times 0.41$ & $0.17 \times 0.17 \times 0.29$ & $0.11 \times 0.17 \times 0.29$ \\
\hline$\mu / \mathrm{mm}^{-1}$ & 0.10 & 2.906 & 0.274 & 0.088 \\
\hline Radiation $\lambda(\AA)$ & 0.71073 & 0.71073 & 0.71073 & 0.71073 \\
\hline$T_{\min } / T_{\max }$ & $0.9559 / 0.9810$ & $0.3792 / 0.7074$ & $0.9238 / 0.9549$ & $0.9753 / 0.9907$ \\
\hline Reflections measured & 7119 & 9227 & 16261 & 33624 \\
\hline Ranges/indices $(h, k, l)$ & $\begin{array}{c}-16,16 ;-8,8 \\
-22,24\end{array}$ & $\begin{array}{c}-8,7 ;-15,15 \\
-24,24\end{array}$ & $\begin{array}{l}-8,8 ;-16,17 \\
\quad-22,27\end{array}$ & $\begin{array}{c}-13,11 ;-18,18 \\
-18,18\end{array}$ \\
\hline$\theta \operatorname{limit}\left(^{\circ}\right)$ & $2.4-30.1$ & $2.2-27.5$ & $2.0-30.2$ & $1.6-30.1$ \\
\hline Unique reflections & 1866 & 2748 & 4340 & 9058 \\
\hline $\begin{array}{l}\text { Observed reflections } \\
\qquad(I>2 \sigma(I))\end{array}$ & 1847 & 2600 & 3706 & 5096 \\
\hline Parameters & 181 & 172 & 200 & 399 \\
\hline Goodness of fit on $F^{2}$ & 1.07 & 1.131 & 1.047 & 1.043 \\
\hline$R_{1}, w R_{2}[I \geq 2 \sigma(I)]$ & $0.0267,0.0748$ & $0.0672,0.1814$ & $0.0341,0.1010$ & $0.0628,0.1538$ \\
\hline
\end{tabular}

Figure 1. (a)-(d) ORTEP diagrams of 1-4 drawn at 50\% ellipsoids for non-hydrogen atoms.

(a)

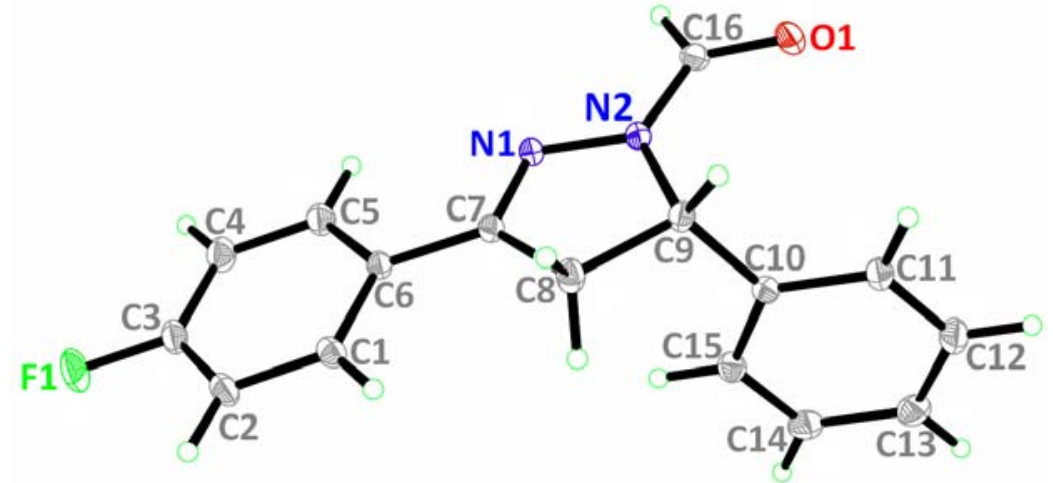


Figure 1. Cont.

(b)

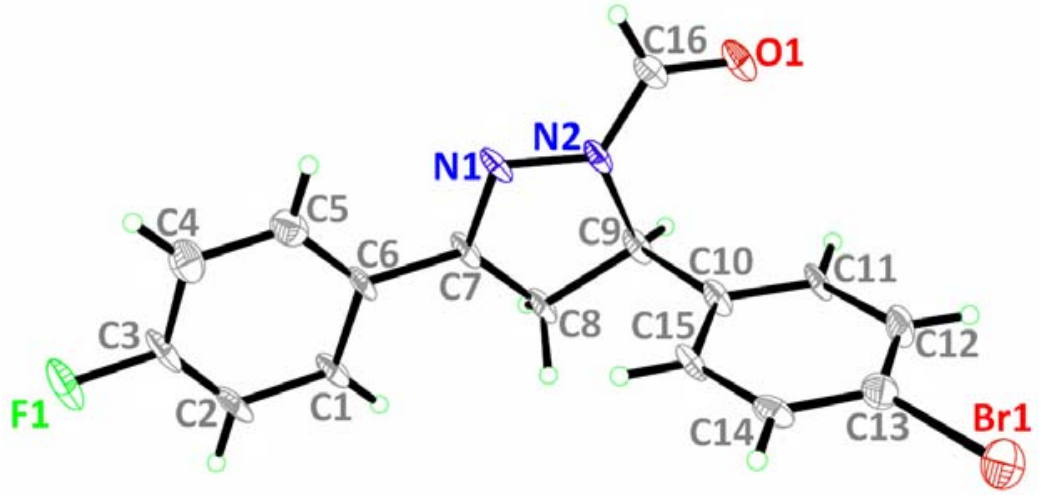

(c)

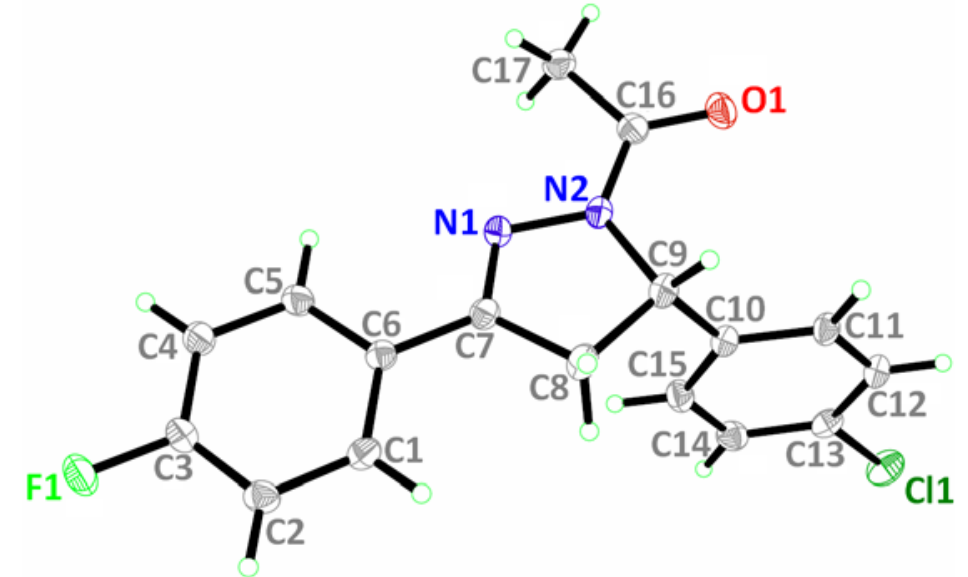

(d)

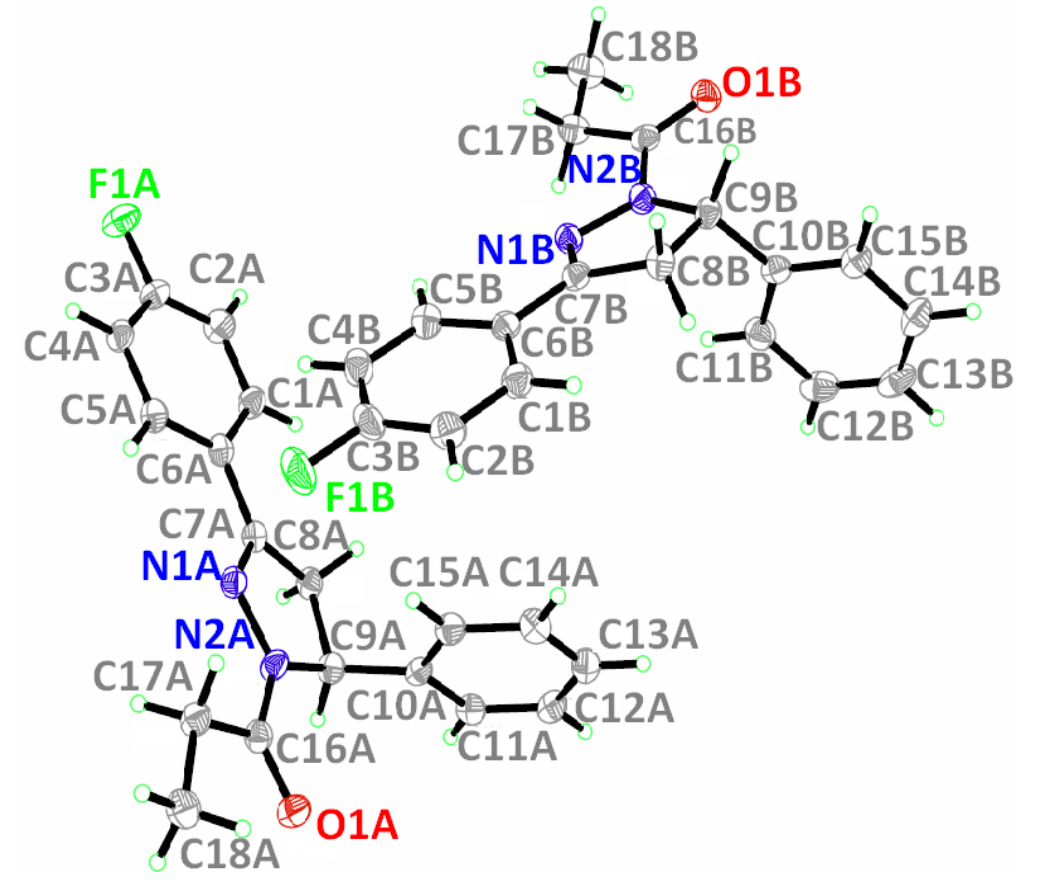


Figure 2. (a)-(b) Crystal structure of compound 1 with intermolecular hydrogen bonding patterns shown as dashed lines. $\mathrm{H}$ atoms not involved in the crystal structure have been omitted for clarity.

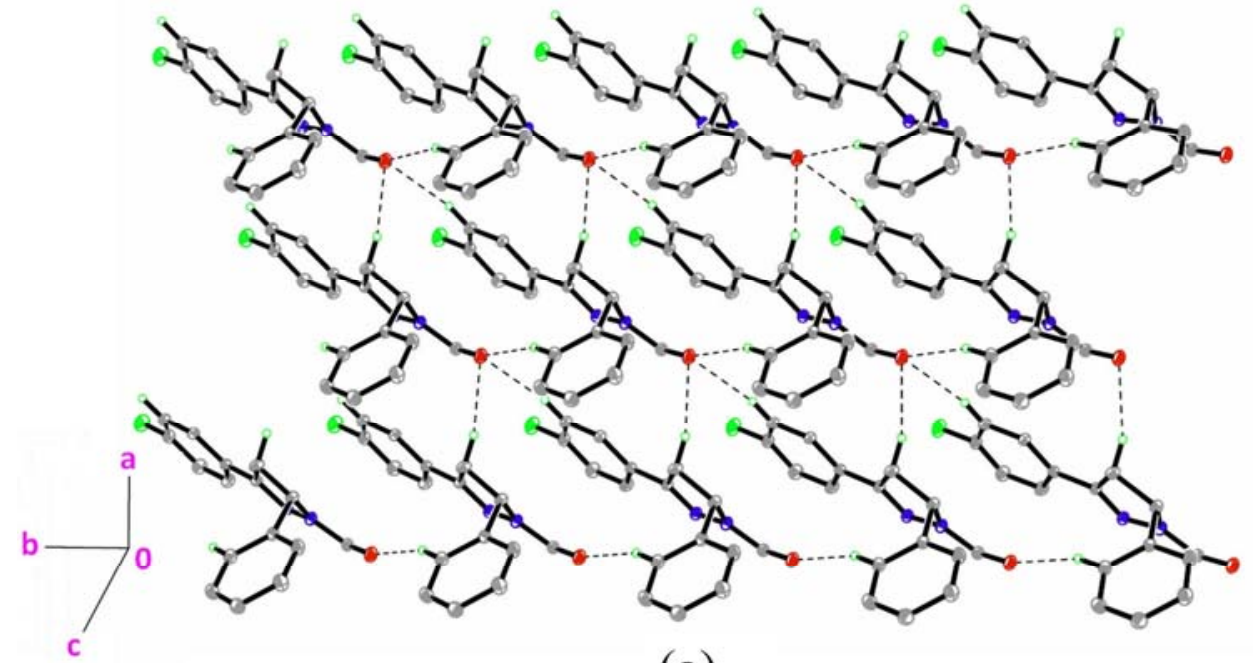

(a)

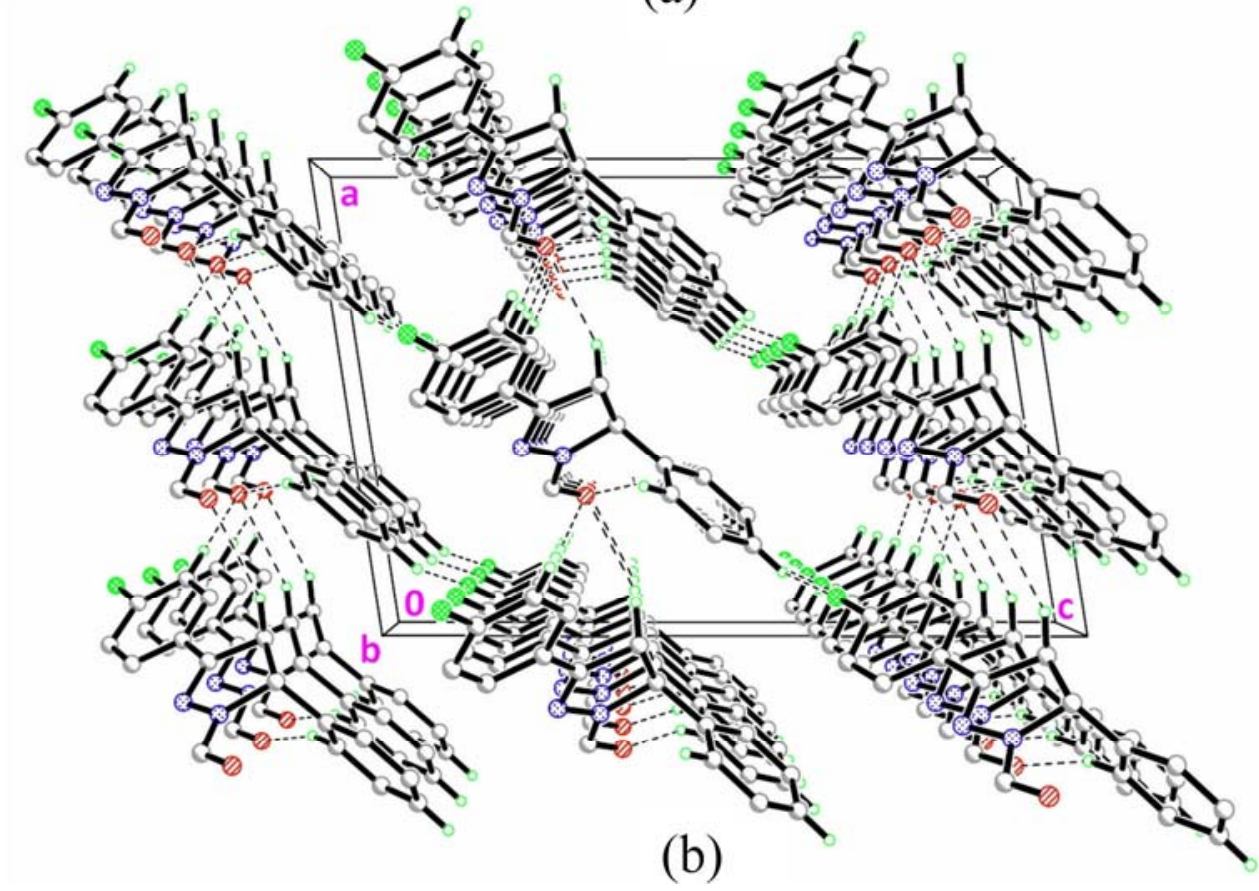

Table 2. Hydrogen bond geometries for compounds (1), (2), (3) and (4).

\begin{tabular}{ccccc}
\hline $\boldsymbol{D}-\mathrm{H} \cdots \boldsymbol{A}$ & $\boldsymbol{d}(\boldsymbol{D}-\mathbf{H})(\AA)$ & $\boldsymbol{d}(\mathbf{H} \cdots \boldsymbol{A})(\AA)$ & $\boldsymbol{d}(\boldsymbol{D} \cdots \boldsymbol{A})(\AA)$ & Angle $(\boldsymbol{D}-\mathbf{H} \cdots \boldsymbol{A})\left({ }^{\circ}\right)$ \\
\hline$(1)$ & & & & \\
$\mathrm{C} 2-\mathrm{H} 2 \mathrm{~A} \cdots \mathrm{O} 1^{\mathrm{i}}$ & 0.95 & 2.36 & $3.2950(16)$ & 166 \\
$\mathrm{C} 8-\mathrm{H} 8 \mathrm{~B} \cdots \mathrm{O} 1^{\mathrm{ii}}$ & 0.99 & 2.60 & $3.5011(16)$ & 151 \\
$\mathrm{C} 13-\mathrm{H} 13 \mathrm{~A} \cdots \mathrm{F}{ }^{\mathrm{iii}}$ & 0.95 & 2.53 & $3.1809(17)$ & 126 \\
$\mathrm{C} 15-\mathrm{H} 15 \mathrm{~A} \cdots \mathrm{O} 1^{\text {iv }}$ & 0.95 & 2.36 & $3.2691(17)$ & 161 \\
$(2)$ & & & & \\
$\mathrm{C} 2-\mathrm{H} 2 \mathrm{~A} \cdots \mathrm{O} 1^{\mathrm{v}}$ & 0.95 & 2.37 & $3.305(10)$ & 167 \\
$\mathrm{C} 12-\mathrm{H} 12 \mathrm{~A} \cdots \mathrm{F} 1^{\mathrm{vi}}$ & 0.95 & 2.48 & $3.322(10)$ & 148 \\
$\mathrm{C} 15-\mathrm{H} 15 \mathrm{~A} \cdots \mathrm{O} 1^{\mathrm{vii}}$ & 0.95 & 2.37 & $3.257(10)$ & 155 \\
\hline
\end{tabular}


Table 2. Cont.

\begin{tabular}{|c|c|c|c|c|}
\hline$D-\mathbf{H} \cdots A$ & $d(D-H)(\AA)$ & $d(\mathrm{H} \cdots A)(\AA)$ & $d(D \cdots A)(\AA ̊)$ & $\operatorname{Angle}(D-\mathbf{H} \cdots A)\left({ }^{\circ}\right)$ \\
\hline \multicolumn{5}{|l|}{ (3) } \\
\hline $\mathrm{C} 2-\mathrm{H} 2 \mathrm{~A} \cdots \mathrm{O} 1 \mathrm{v}^{\mathrm{iii}}$ & 0.93 & 2.43 & $3.2492(14)$ & 147 \\
\hline $\mathrm{C} 14-\mathrm{H} 14 \mathrm{~A} \cdots \mathrm{F} 1^{\text {ix }}$ & 0.93 & 2.49 & $3.3462(14)$ & 154 \\
\hline $\mathrm{C} 15-\mathrm{H} 15 \mathrm{~A} \cdots \mathrm{O} 1^{\mathrm{x}}$ & 0.93 & 2.52 & $3.4282(14)$ & 166 \\
\hline \multicolumn{5}{|l|}{ (4) } \\
\hline $\mathrm{C} 1 \mathrm{~A}-\mathrm{H} 1 \mathrm{AA} \cdots \mathrm{O} 1 \mathrm{~B}{ }^{\mathrm{xi}}$ & 0.95 & 2.43 & $3.324(2)$ & 156 \\
\hline C1B-H1BA $\cdots$ O1A & 0.95 & 2.43 & $3.223(2)$ & 141 \\
\hline C9B-H9BA $\cdots$ O1A ${ }^{\text {xiii }}$ & 1.00 & 2.56 & $3.345(2)$ & 135 \\
\hline $\mathrm{C} 15 \mathrm{~B}-\mathrm{H} 15 \mathrm{~B} \cdots \mathrm{O} 1 \mathrm{~A}^{\mathrm{iv}}$ & 0.95 & 2.48 & $3.349(2)$ & 151 \\
\hline
\end{tabular}

\subsection{Crystal Structure Description of Compound 2}

Figure $1 \mathrm{~b}$ shows the molecular structure of 2 . The pyrazole ring (N1/N2/C7-C9) with r.m.s deviation of $0.0434 \AA$ is almost coplanar with the fluoro-substituted benzene ring (C1-C6) with a dihedral angle of 5.3(4) $)^{\circ}$ and it is almost perpendicular with the bromo-substituted benzene ring $(\mathrm{C} 10-\mathrm{C} 15)$ with a dihedral angle of $85.1(4)^{\circ}$ which is identical to that of compound $\mathbf{1}$. Bond lengths and angles are within the normal ranges [16]. The crystal structure of $\mathbf{2}$ is shown in Figure 3. Intermolecular $\mathrm{C}-\mathrm{H} \bullet \bullet \mathrm{O}$ hydrogen bonds (Table 2) link the molecules to form planes parallel to the $a b$-plane as shown in Figure 3a. These planes are further inter-connected into a three-dimensional network via $\mathrm{C}-\mathrm{H} \bullet \bullet \mathrm{F}$ hydrogen bonds (Table 2; Figure 3b).

Figure 3. (a)-(b) Crystal structure of compound 2 with intermolecular hydrogen bonding patterns shown as dashed lines. $\mathrm{H}$ atoms not involved in the crystal structure have been omitted for clarity.

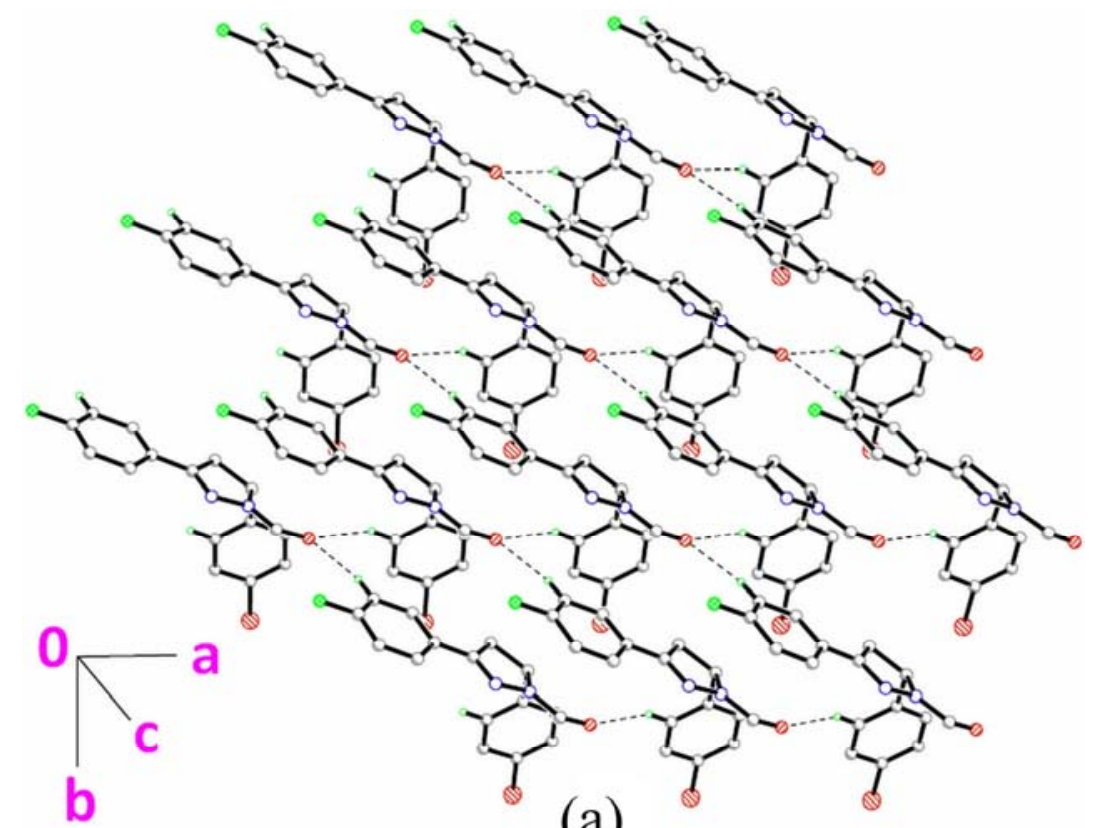

(a) 
Figure 3. Cont.

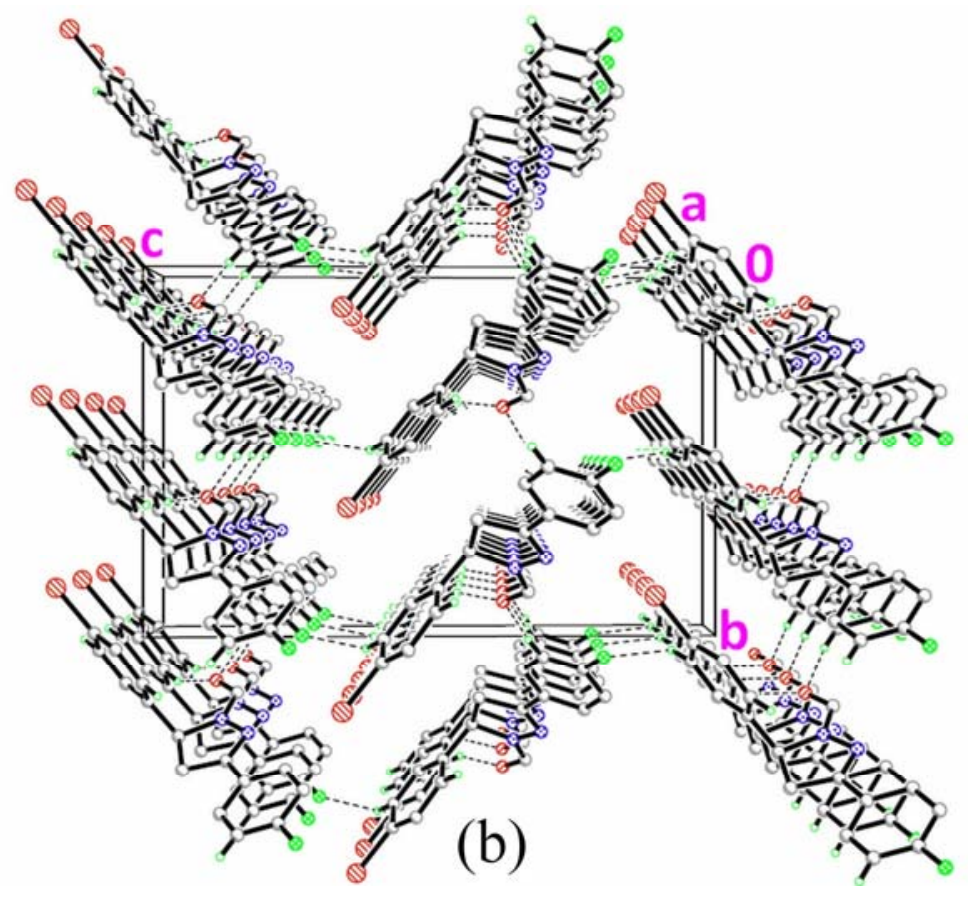

\subsection{Crystal Structure Description of Compound $\mathbf{3}$}

The molecular structure of 3 is given in Figure 1c. The pyrazole ring (N1/N2/C7-C9) with r.m.s deviation of $0.0259 \AA$, forms dihedral angles of $4.89(6)$ and $85.76(6)^{\circ}$, respectively, with the fluoroand chloro-substituted benzene rings (C1-C6 \& $\mathrm{C} 10-\mathrm{C} 15)$. Bond lengths and angles are within the normal ranges [16]. Figure 4 shows the crystal structure of $\mathbf{3}$. The molecules are linked together via two $\mathrm{C}-\mathrm{H} \bullet \bullet \mathrm{O}$ and one $\mathrm{C}-\mathrm{H} \bullet \bullet \mathrm{F}$ hydrogen bonds (Table 2), generating $R_{3}^{2}(9)$ ring motifs [17] and form planes parallel to the $a b$-plane.

Figure 4. (a)-(b) Crystal structure of compound 3 with intermolecular hydrogen bonding patterns shown as dashed lines. $\mathrm{H}$ atoms not involved in the crystal structure have been omitted for clarity.

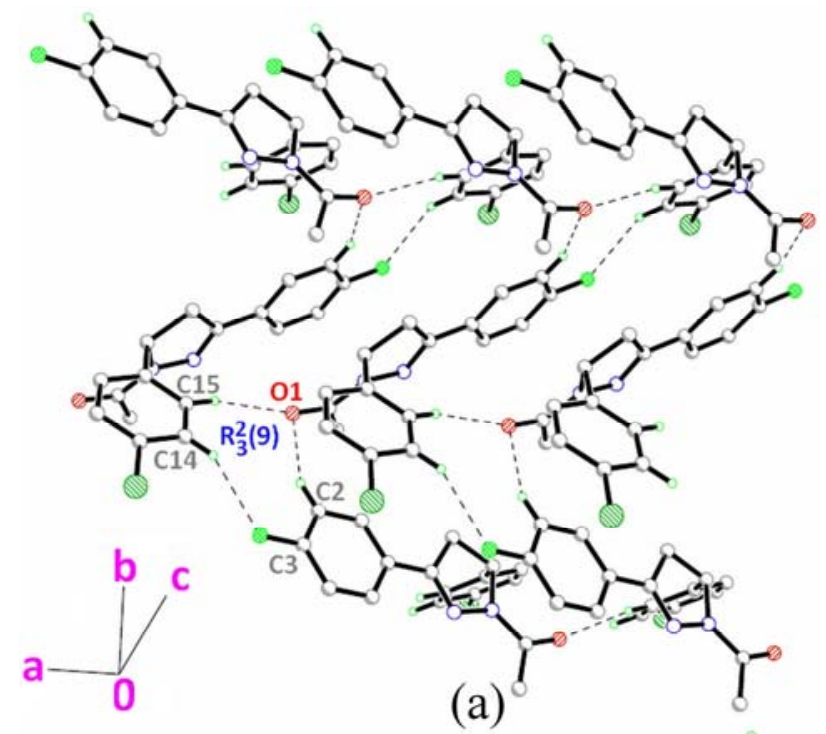


Figure 4. Cont.

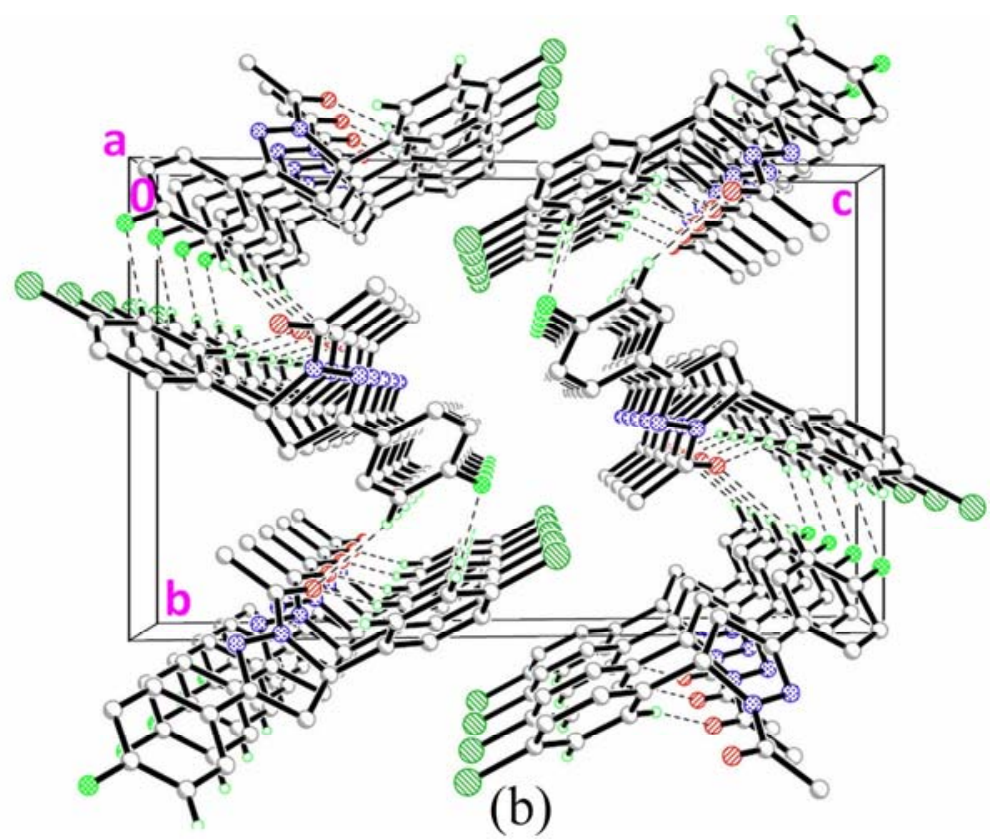

\subsection{Crystal Structure Description of Compound 4}

Figure 1d shows the molecular structure of 4 , which contains two crystallographically independent molecules, namely molecules $A$ and $B$. The pyrazole rings (N1/N2/C7-C9) in both molecules are almost planar with r.m.s. deviations of $0.0425 \AA$ for $A$ and $0.0333 \AA$ for $B$. In molecule $A$, the pyrazole ring forms dihedral angles of $10.53(10)^{\circ}$ with the fluoro-substituted benzene ring $(\mathrm{C} 1 \mathrm{~A}-\mathrm{C} 6 \mathrm{~A})$ and $80.63(10)^{\circ}$ with the benzene ring $(\mathrm{C} 10 \mathrm{~A}-\mathrm{C} 15 \mathrm{~A})$. In molecule $B$, the corresponding dihedral angles are 9.78(10) and $79.78(10)^{\circ}$. Bond lengths and angles are within the normal ranges [16]. In the crystal structure of 4 (Figure 5a), molecules $A$ and $B$ are interlinked via C9B-H9BA $\bullet O \mathrm{O} 1 \mathrm{~A}$ and C15B-H15B・•O1A hydrogen bonds (Table 2) to form $R_{2}^{1}(6)$ ring motifs [17] which play a role in stabilizing the crystal structure. These sets of ring motifs are then linked into chains along the [0 $0 \overline{1}$ ] as shown in Figure 5b via intermolecular $\mathrm{C} 1 \mathrm{~A}-\mathrm{H} 1 \mathrm{AA} \cdot \cdots \mathrm{O} 1 \mathrm{~B}$ and $\mathrm{C} 1 \mathrm{~B}-\mathrm{H} 1 \mathrm{BA} \cdot \cdots \mathrm{O} 1 \mathrm{~A}$ hydrogen bonds (Table 2).

Figure 5. (a)-(b) Crystal structure of compound 4 with intermolecular hydrogen bonding patterns shown as dashed lines. $\mathrm{H}$ atoms not involved in the crystal structure have been omitted for clarity.

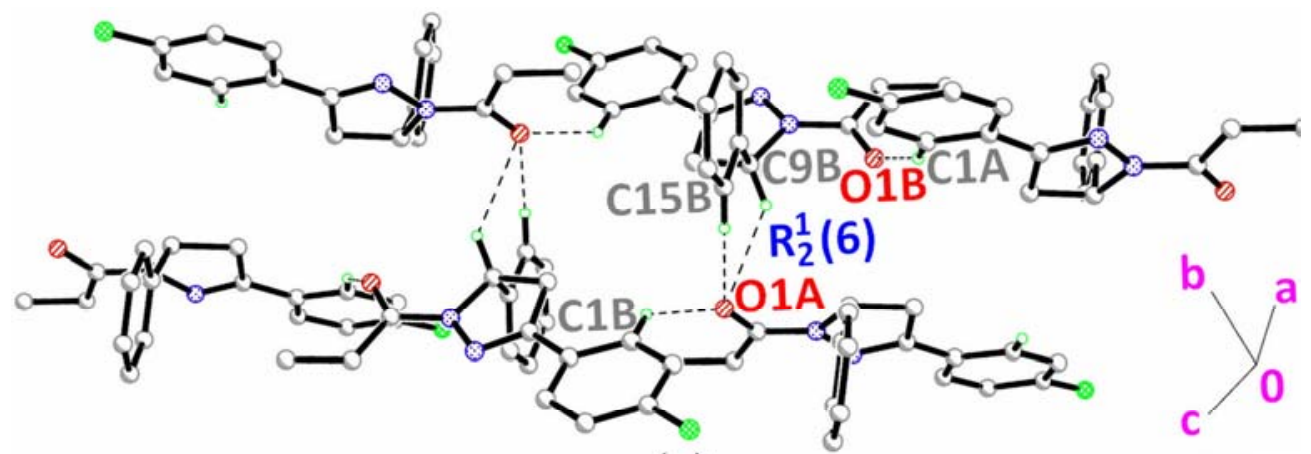

(a) 
Figure 5. Cont.

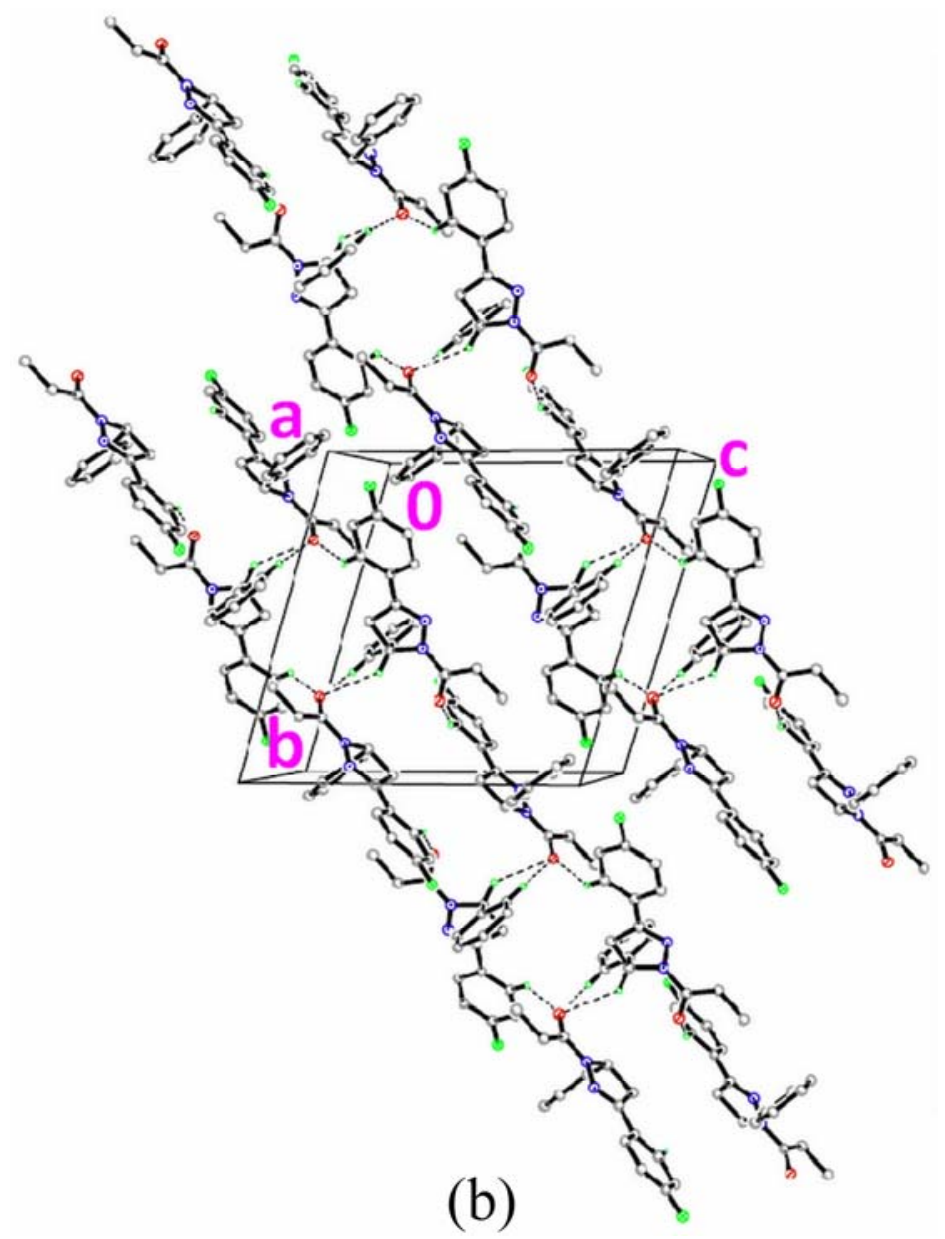

\section{Experimental}

\subsection{Materials and Method}

X-ray diffraction studies were carried out using the Bruker SMART Apex II and Apex II Duo CCD diffractometers. Melting points were taken in open capillary tubes and were uncorrected. The purity of the compounds was confirmed by thin layer chromatography using Merck silica gel $60 \mathrm{~F}_{254}$ coated aluminium plates. Elemental analyses were carried out by using VARIO EL-III (Elementar Analysensysteme GmBH, Hanau, Germany).

\subsection{General Procedure for the Synthesis of N-Substituted Pyrazolines}

A mixture of substituted chalcone $(0.01 \mathrm{~mol})$ and hydrazine hydrate $(0.5 \mathrm{~mL}, 0.01 \mathrm{~mol})$ in $25 \mathrm{~mL}$ formic or acetic or propionic acid was refluxed for $8 \mathrm{~h}$. The reaction mixture was cooled and poured into $50 \mathrm{~mL}$ ice-cold water. The precipitate was collected by filtration and purified by recrystallization from ethanol. The crystals were grown by the slow evaporation method.

3-(4-Fluorophenyl)-5-phenyl-4,5-dihydro-1H-pyrazole-1-carbaldehyde (1). Solvent for recrystallization: acetone; Yield: 87\%; m.p. 154-157 ${ }^{\circ} \mathrm{C}$; Analytical data: Found (Cald): C\%: 71.60 (71.63); H\%: 4.91 (4.88); N\%: $10.41(10.44)$. 
5-(4-Bromophenyl)-3-(4-fluorophenyl)-4,5-dihydro-1H-pyrazole-1-carbaldehyde (2). Solvent for recrystallization: toluene; Yield: 78\%; m.p. 99-101 ${ }^{\circ} \mathrm{C}$; Analytical data: Found (Cald): C\%: 55.32 (55.35); H\%: 3.50 (3.48); N\%: 8.03 (8.07).

1-[5-(4-Chlorophenyl)-3-(4-fluorophenyl)-4,5-dihydro-1H-pyrazol-1-yl]ethanone (3). Solvent for recrystallization: ethanol; Yield: 72\%; m.p. $110-112{ }^{\circ} \mathrm{C}$; Analytical data: Found (Cald): C\%: 64.42 (64.46); H\%: 4.49 (4.45); N\%: 8.80 (8.84).

1-[3-(4-Fluorophenyl)-5-phenyl-4,5-dihydro-1H-pyrazol-1-yl]propan-1-one (4). Solvent for recrystallization: acetone; Yield: 67\%; m.p. $113-115{ }^{\circ} \mathrm{C}$; Analytical data: Found (Cald): C\%: 72.95, (72.97); H\%: 5.78, (5.81); N\%: 9.45 (9.40).

\subsection{X-ray Crystallographic Analysis}

Selected crystals were mounted on glass fibers and intensity data were collected using either Bruker SMART Apex II or Apex II Duo CCD diffractometer. The data for these compounds were processed with SAINT and corrected for absorption using SADABS. The structures of the compounds were solved by direct method using the program SHELXTL [18], and were refined by full-matrix least squares technique on $F^{2}$ using anisotropic displacement parameters. The non-hydrogen atoms were refined anisotropically. All the $\mathrm{H}$ atoms in these compounds were calculated geometrically with isotropic displacement parameters set to 1.2 (1.5 for methyl groups) times the equivalent isotropic $U$ values of the parent carbon atoms. A rotating group model was applied to the methyl groups. Hydrogen bonding interactions are shown in Table 2. CCDC 895315 for (1), 895316 for (2), 895317 for (3) and 895318 for (4) contain the supplementary crystallographic data for this paper. These data can be obtained free of charge at http://www.ccdccam.ac.uk/const/retrieving.html or from the Cambridge Crystallographic Data Centre (CCDC), 12 Union Road, Cambridge CB2 1EZ, UK; fax: +44(0)1223-336033 or e-mail: deposit@ccdc.cam.ac.uk.

\section{Conclusions}

The crystal and molecular structures of 3-(4-fluorophenyl)-5-phenyl-4,5-dihydro- $1 H$-pyrazole-1carbaldehyde (1), 5-(4-bromophenyl)-3-(4-fluorophenyl)-4,5-dihydro-1H-pyrazole-1-carbaldehyde (2), 1-[5-(4-chlorophenyl)-3-(4-fluorophenyl)-4,5-dihydro-1H-pyrazol-1-yl]ethanone (3) and 1-[3-(4fluorophenyl)-5-phenyl-4,5-dihydro-1H-pyrazol-1-yl]propan-1-one (4) are reported. These data represent the confirmation of the structures of the four newly reported $N$-substituted pyrazoline compounds.

\section{Acknowledgments}

The authors extend their appreciation to The Deanship of Scientific Research at King Saud University for the funding the work through the research group project No. RGP-VPP-207.

\section{References}

1. Samshuddin, S.; Narayana, B.; Sarojini, B.K.; Khan, M.T.H.; Yathirajan, H.S.; Raj, C.G.D.; Raghavendra, R. Antimicrobial, analgesic, DPPH scavenging activities and molecular docking study of some 1,3,5-triaryl-2-pyrazolines. Med. Chem. Res. 2012, 21, 2012-2022. 
2. Jasinski, J.P.; Golen, J.A.; Samshuddin, S.; Narayana, B.; Yathirajan, H.S. Synthesis, characterization and crystal structures of 3,5-bis(4-fluorophenyl)-4,5-dihydro- $1 H$-pyrazole-1-carboxamide and 3,5-Bis(4-fluorophenyl)-4,5-dihydro-1H-pyrazole-1-carbothioamide. Crystals 2012, 2, 1108-1115.

3. Samshuddin, S.; Narayana, B.; Baktir, Z.; Akkurt, M.; Yathirajan, H.S. Synthesis, characterization and crystal structure of 1-[3,5-bis(4-fluorophenyl)-4,5-dihydro-1H-pyrazol-1-yl]propan-1-one. Der Pharma Chemica 2011, 3, 487-493.

4. Azarifar, D.; Ghasemnejad, H. Microwave-assisted synthesis of some 3,5-arylated 2-pyrazolines. Molecules 2003, 8, 642-648.

5. Sharshira, E.M.; Hamada, N.M.M. Synthesis and antimicrobial evaluation of some pyrazole derivatives. Molecules 2012, 17, 4962-4971.

6. Kant, R.; Gupta, V.G.; Kapoor, K.; Sapnakumari, M.; Sarojini, B.K.; Narayana, B. (1Z)-1-[(2E)3-(4-bromophenyl)-1-(4-fluorophenyl)prop-2-en-1-ylidene]-2-(2,4-dinitrophenyl)hydrazine. Acta Crystallogr. E 2012, 68, o2193.

7. Amir, M.; Kumar, H.; Khan, S. Synthesis and pharmacological evaluation of pyrazoline derivatives as new anti-inflammatory and analgesic agents. Bioorg. Med. Chem. Lett. 2008, 18, 918-922.

8. Hes, R.V.; Wellinga, K.; Grosscurt, A.C. 1-Phenylcarbamoyl-2-pyrazolines: A new class of insecticides. 2. Synthesis and insecticidal properties of 3,5-diphenyl-1-phenylcarbamoyl-2pyrazolines. J. Agric. Food Chem. 1978, 26, 915-918.

9. Rahman, M.A.; Siddiqui, A.A. Pyrazoline Derivatives: A Worthy insight into the recent advances and potential pharmacological activities. Int. J. Pharm. Sci. Drug Res. 2010, 2, 165-175.

10. Wiley, R.H.; Jarboe, C.H.; Hayes, F.N.; Hansbury, E.; Nielsen, J.T.; Callahan, P.X.; Sellars, M. 1,3,5-Triaryl-2-pyrazolines for use as scintillation solutes. J. Org. Chem. 1958, 23, 732-738.

11. Zhang, X.H.; Wu, S.K.; Gao, Z.Q.; Lee, C.S.; Lee, S.T.; Kwong, H.L. Pyrazoline derivatives for blue color emitter in organic electroluminescent devices. Thin Solid Films 2000, 371, 40-46.

12. Fun, H.K.; Ooi, C.W.; Sapnakumari, M.; Narayana, B.; Sarojini, B.K. 1-[3-(4-Fluorophenyl)-5phenyl-4,5-dihydro-1H-pyrazol-1-yl]ethanone. Acta Crystallogr. E 2012, 68, o2634.

13. Fun, H.K.; Loh, W.S.; Sapnakumari, M.; Narayana, B.; Sarojini, B.K. 1-[5-(4-Bromophenyl)-3(4-fluorophenyl)-4,5-dihydro-1H-pyrazol-1-yl]ethanone. Acta Crystallogr. E 2012, 68, o2586.

14. Fun, H.K.; Loh, W.S.; Sapnakumari, M.; Narayana, B.; Sarojini, B.K. 1-[5-(4-Bromophenyl)-3-(4fluorophenyl)-4,5-dihydro-1H-pyrazol-1-yl]butan-1-one. Acta Crystallogr. E 2012, 68, o2655-2656.

15. Fun, H.K.; Chia, T.S.; Sapnakumari, M.; Narayana, B.; Sarojini, B.K. 5-(4-Bromophenyl)-3-(4fluorophenyl)-1-phenyl-4,5-dihydro-1H-pyrazole. Acta Crystallogr. E 2012, 68, o2680.

16. Allen, F.H.; Kennard, O.; Watson, D.G.; Brammer, L.; Orpen, A.G.; Taylor, R. Tables of bond lengths determined by $X$-ray and neutron diffraction. Part 1. Bond lengths in organic compounds. J. Chem. Soc. Perkin Trans. 1987, 2, S1-S19.

17. Bernstein, J.; Davis, R.E.; Shimoni, L.; Chang, N.L. Patterns in hydrogen bonding: Functionality and graph set analysis in crystals. Angew. Chem. Int. Edit. Engl. 1995, 34, 1555-1573.

18. Sheldrick, G.M. A short history of SHELX. Acta Crystallogr. A 2008, 64, 112-122.

Sample Availability: Samples of the compounds are available from the authors.

(C) 2013 by the authors; licensee MDPI, Basel, Switzerland. This article is an open access article distributed under the terms and conditions of the Creative Commons Attribution license (http://creativecommons.org/licenses/by/3.0/). 